\title{
A qualitative evaluation of a visiting scholar program between Brazil and Canada
}

\author{
J udy Ellen Mill' ${ }^{1}$, Leanne C J ohnson ${ }^{1}$, I sabel Amelia Costa Mendes ${ }^{2}$, Carla A. Arena Ventura ${ }^{2}$, \\ Emanuele Seicenti Brito ${ }^{2}$
}

1. Faculty of Nursing, University of Alberta, Edmonton, Canada. 2. College of Nursing, University of São Paulo at Ribeirão Preto, Ribeirão Preto, Brazil.

Correspondence: Judy Ellen Mill. Address: Faculty of Nursing, University of Alberta, Edmonton, Canada. Email: judy.mill@ualberta.ca

Received: November 18, 2013

Accepted: December 5, $2013 \quad$ Online Published: January 22, 2014

DOI : $10.5430 /$ jnep.v4n3p252

URL: http://dx.doi.org/10.5430/jnep.v4n3p252

\section{Abstract}

Background: International experiences provide a rich, transformative learning opportunity and are fundamental to the internationalization of universities that is occuring globally. To date there has been limited research to evaluate the experiences of, and benefits to, faculty members who participate in an international experience. In the current paper, we report findings from the evaluation of a Visiting Scholar Program (VSP) between the University of São Paulo at Ribeirão Preto College of Nursing (EERP-USP), Brazil and the Faculty of Nursing, University of Alberta (UA), Canada. The VSP was initiated in 2004, with a generous donation from a private donor, as one component of a broader partnership between the two university schools of nursing.

Methods: The evaluation of the VSP program was carried out between January and June 2011 using a qualitative approach. An interpretative descriptive design was used for the study and in-depth interviews were used to collect the data. At the UA, 17 individuals affiliated with the Brazil project participated in an interview and two provided email feedback. At EERP-USP, 12 former scholars, one graduate student, two staff members responsible for the International Cooperation Office, and a former Dean participated in the evaluation.

Results: Several key themes emerged during the analysis of the interviews. The program was highly successful from the perspective of both scholars and supervisors alike. The commitment to internationalization at each site, the wellestablished partnership between EERP-USP and UA, and the financial resources available all contributed to the provision of a supportive, enabling environment for the scholars to develop their own research capacity and for both scholars and supervisors to build new research networks. Participants commented on the importance of personal relationships and convergent research interests between scholars and the supervisors. Several challenges related to language, length of the program, and at times, inadequate pre-planning between the scholar and supervisor were identified by participants.

Conclusion: Overall the leadership team at each site and the scholars and supervisors believed that the VSP was successful. Despite several challenges, supervisors and scholars alike benefited from ongoing relationships and were appreciative of the opportunities for professional growth and research development that participation in the VSP program provided. Recommendations for future similar programs include: commitment to internationalization; a well-established 
partnership between the two sites; sufficient financial resources; language training; a 12 month program if possible; good fit between scholar and supervisor; and pre-planning.

\section{Key words}

International, Partnership, Visiting scholar, Brazil, Canada, Qualitative research, Evaluation

\section{I ntroduction}

Internationalization is central to the strategic plans of universities around the world and “...is occurring within the context of globalization” ${ }^{[1, p .73]}$. Nurses are integral to improving the health of individuals, families and communities worldwide; therefore it is critical for nursing programs to be actively involved in addressing global health challenges by promoting a deeper understanding of global citizenship ${ }^{[2]}$ and the political and economic dimensions of health ${ }^{[1]}$. International exchanges between faculty and students have been identified as one strategy to strengthen nursing care, education and

research ${ }^{[3,4]}$. Participating in an international experience provides an opportunity to develop a deeper understanding of the principles of global citizenship and can increase research capacity, collaboration and partnership. Most of the research to evaluate international nursing exchanges has focused on undergraduate student programs, with limited research to evaluate the experiences of and benefits to faculty ${ }^{[3]}$. In the current paper, we report findings from the evaluation of a Visiting Scholar Program (VSP) between faculty at the University of São Paulo at Ribeirão Preto College of Nursing (EERP-USP), Brazil and the Faculty of Nursing, University of Alberta (UA), Canada. The findings reported here provide critical insights and enhance the body of knowledge about international programs at the visiting scholar and faculty level.

\subsection{Background}

The VSP was initiated in 2004 with a generous donation from a private donor. The Academic Visitor's Office at UA recommended the classification "Visiting Scholar" for scholars in the VSP. However, because many faculty members at UA and EERP-USP were familiar with the term post-doctoral fellow (PDF), and the visiting scholars had completed doctoral work, the term PDF is occasionally used by participants in the interviews to describe the program. The VSP is one component of a broader partnership between the two university schools of nursing. The aim of this international partnership is to develop and strengthen collaborative relations between the two institutions. Each university agreed to meet this objective through faculty and student mobility programs and exchanges, joint research activities and publications, faculty development and capacity building.

By the end of 2011, 15 visiting scholars from EERP-USP had completed a fellowship at the UA. Eleven of these scholars were funded by the project donor. Department heads at EERP-USP were responsible for selecting scholars, with input from members of the Global Nursing Office at UA. The momentum created by the VSP has also drawn interest from scholars at other Brazilian universities, who were successful in funding applications to research organizations in Brazil, enabling additional scholars to visit UA. In addition, graduate students from EERP-USP have also been successful in securing funds to support periods of training at UA. These students, enrolled in the doctoral program at EERP, were granted a 'sandwich fellowship' to spend 4-6 months at the UA for additional research training. Alternate sources of funding for these scholars include São Paulo Research Foundation and Coordination for the Improvement of Higher Education Personnel. Although it is important to note the additional partnerships that have developed as a result of the VSP, the findings in this paper focus on the experience of the visiting scholars funded by the private donor.

\subsection{Literature review}

The overall goal of the Brazil VSP was to promote capacity building in nursing research and the production of knowledge to influence policy and practice. It was anticipated that the VSP would be mutually beneficial by assisting EERP-USP to develop the capacity to mentor other Latin America Schools of Nursing in research training and enabling both universities to build and enhance international research collaboration at the individual and faculty level. The development of research 
capacity is critical in low and middle income countries (LMIC) to ensure that research agendas are driven by local needs and by persons who understand the local context ${ }^{[5-8]}$. Research capacity is enhanced through: mentorship and partnership ${ }^{[9-13]}$; consistent communication within the team ${ }^{[14]}$; government commitment to the research ${ }^{[15]}$; the involvement of key decision makers and stakeholders ${ }^{[16]}$; and when deliberate efforts to leverage personal and institutional relationships are made ${ }^{[17]}$.

Although individual training is fundamental, the development of an enabling environment, including local leadership, infrastructure, information access and interface between research producers and users, are also critical components in the development of research capacity ${ }^{[7]}$. Potter and Brough ${ }^{[18]}$ provide an excellent analysis of capacity building within health sectors in LMIC countries. They argue that technical skills are only one component of capacity and stress the importance of addressing "systemic capacity building, identifying a pyramid of nine separate but interdependent components" (p. 336) that include performance, personal, workload, supervisory, facility, support service, systems, structural, and role capacities.

Several authors ${ }^{[8,19]}$ have argued that investments in health research and development ultimately contribute to the improvement in the health status of populations. Furthermore, developing the capacity of local researchers is critical to ensure that research priorities of LMIC countries are met and sustainable partnerships are developed ${ }^{[19]}$. Differing research priorities among partners “....must be balanced between international and national relevance and research-driven and policy-driven concerns” ${ }^{[20, \text { p.11] }}$.

McAuliffe and Cohen ${ }^{[4]}$ reviewed 79 articles that described international nursing education exchange programs between 1996 and 2003. The authors reported that most of the articles (89\%) provided a descriptive account of the experience, involved students (46\%) or faculty (40\%), and were authored by faculty $(71 \%)$ and an individual on one side of the exchange (78\%). More recently, Kulbok and colleagues ${ }^{[21]}$ conducted a systematic review of international nursing education and student experiences. The authors reported that of the 23 articles meeting the review criteria, most focused on student experiences, with only one research article focusing on nursing PhD students and faculty. Similar to the earlier review conducted by McAuliffe and Cohen, these authors also noted that the majority of the papers evaluating these experiences were authored by researchers on one side of the partnership rather than by all partners in the international experience. Based on the review, Kubok and colleagues recommend ensuring that: the partnership involves mutual goal setting and is two way; there are adequate resources for the international experience; and there is a collaborative process to resolve concerns.

A descriptive qualitative research study explored the experiences of Jordanian nursing faculty members who participated in an exchange with Sweden ${ }^{[3]}$. The authors highlighted the importance of both partners being involved in the planning of the visit to identify when the faculty member would arrive, who they would work with, as well as the objectives and purpose of their visit. The authors stated that it is important to select a person who is suitable for the experience and not select someone based on "personal inclination or workload" (p.185). The authors also reported that Jordanian faculty experienced difficulty implementing the learning that occurred during the exchange upon return to their home country. There is a critical need to evaluate international nursing educational experiences ${ }^{[21]}$. The purpose of the current study was to evaluate the outcomes of the VSP, including challenges to implementation, and the recommendations for future programs. In this paper we present findings related to the outcomes and challenges of the VSP, particularly in relation to advancing scholarship among faculty members involved in the VSP. Findings related to the cross-cultural experiences of participants in the VSP program and recommendations for future programs are reported elsewhere ${ }^{[22]}$.

\section{Methods}

In 2009, the Deans from both schools met in Brazil to discuss the feasibility of conducting research to evaluate the VSP program. As a result, the Brazil VSP Evaluation Project was developed. All of the supervisors at UA and scholars from 
EERP-USP were invited to participate in a qualitative interview between January and June 2011. In addition, staff who had been affiliated with the program and a former Dean at EERP-USP were invited to participate. A qualitative approach, using an interpretative descriptive research design ${ }^{[23,24]}$ was used for the study. An interview format using guiding questions was developed jointly by the research team; a research assistant at each site conducted the interviews with the supervisors and scholars. The interviews were carried out in English at UA and Portuguese at EERP-USP and took from 30 to 60 minutes. The Portuguese interview transcripts were translated into English for analysis by an independent translator who is fluent in both English and Portuguese. Once the translation was completed one member of the Brazilian research team, also fluent in English and Portuguese, checked the transcripts for accuracy. The guiding questions focused on the project strengths, challenges and recommendations for future partnerships. An inductive process was used to analyze the data using Morse's ${ }^{[25]}$ taxonomy including comprehending, synthesizing, theorizing and re-contextualizing the data during face to face meetings with the first four authors. Comprehending refers to learning everything that is possible about the setting, culture and study topic ${ }^{[25]}$. Comprehension in the current study was achieved through the literature review and was enhanced by having investigators from both countries on the research team who were experienced in international projects. Synthesizing refers to sorting the significant from the insignificant findings in order to begin to develop a composite description ${ }^{[25]}$. A coding framework was developed using a small subset of the interviews and with input from investigators and research assistants in each of the study countries to assist with the synthesis of the findings and the identification of key themes. As the analysis process proceeded, the coding framework was refined to reflect new insights about the data and relationships among the themes. Theorizing and recontextualizing of the findings involves the process of linking the findings to established knowledge ${ }^{[25]}$ and took place during virtual and face to face research team meetings that were part of the current project.

\section{Ethics approval}

Approval to conduct the evaluation at the UA was obtained from the Health Research Ethics Board (Panel B) and at EERP-USP by the Research Ethics Committee.

\section{Findings}

At the UA, 17 individuals affiliated with the Brazil project participated in an interview and two provided email feedback. This sample included 12 direct supervisors and five staff. One supervisor declined an interview and one did not respond to the request. At EERP-USP, twelve former scholars, one graduate student, two staff members responsible for the International Cooperation Office, and the former Dean participated. The participating scholars stayed in Edmonton for 6 months to 1 year, with the average period of time being 6.4 months. The scholars' research areas covered a wide range of topics including infectious chronic illness, maternal child health, nursing management, pediatrics, public health, medical nursing, education, ethics and mental health nursing. Scholars had completed their doctoral education from 1 to 10 years prior to beginning the VSP. Typically post-doctoral scholars must have completed their $\mathrm{PhD}$ in the previous 5 years, however two of the scholars from EERP-USP had not had the opportunity to apply for post-doctoral studies, and therefore it had been more than 5 years since the completion of their $\mathrm{PhD}$.

Several key themes emerged during the analysis of the interviews and are presented in this article: 1) factors contributing to success; 2) program challenges; and 3) project outcomes and recommendations for the VSP program in relation to the development of scholarship. In order to protect the anonymity of the participants, they are identified by number and as either 'staff', 'supervisor', 'scholar', 'graduate student', or 'Dean'.

\subsection{Factors contributing to success}

There were a number of factors identified by supervisors, scholars and staff that contributed to the success of the VSP program. 


\subsubsection{Ongoing relationships}

Interestingly, several scholars commented on the partnership between UA and EERP-USP that was well established when the VSP program was implemented. This was a factor that facilitated the scholars' access to the program and provided a foundation for a successful relationship between the scholar and the supervisor. The scholars were keen to "know other researchers” (Scholar \# 3) and develop a “bond with an international institution” (Scholar \# 5).

Most supervisors had a positive experience supervising a scholar from EERP-USP and stated that they would be open to supervising another scholar from that university. One of the staff believed that colleagues at EERP-USP had been instrumental in selecting the most suitable scholars to participate in the VSP. All of the supervisors interviewed were pleased with the professional relationship that developed with the scholars. Most supervisors confirmed that the research interests of the scholar were similar to their own area of expertise. This was considered an absolute necessity for the training to be successful and productive. One of the participants commented on the respect that she had observed between scholars and supervisors:

So there certainly were relationships formed, and relationships are critical in these programs... I don't think getting respect is a huge challenge. I honestly think there's mutual respect, and people-the Brazilian scholars are very warm and appreciative, and the Canadian supervisors are very happy to be assisting them and learning what they can from them. (Staff \#2)

\subsubsection{Alignment with internationalization policy}

Several of the scholars mentioned that they were motivated to participate in the VSP program in order to fulfill the international policy of both their school and the university. The supervisors also spoke of the contribution that the VSP made toward the goal of internationalization in the Faculty of Nursing at UA. For example, one supervisor stated:

I think a program like this is very beneficial to that whole internationalization of our faculty, that this is one piece of it....I really think it's good when faculty are exposed to the program and to have that opportunity to supervise someone from another country. (Supervisor \#12)

Working with a Brazilian scholar may have challenged myths that a supervisor had about LMIC scholars. One supervisor believed that the program may have decreased "stereotyping middle and low income countries as different or backward" (Supervisor \#1). The same supervisor believed that work with Brazilian scholars enabled UA faculty to "bring the international flavor of their work to the international audience" (Supervisor \#1).

\subsubsection{Commitment to professional growth}

Many of the scholars commented on the "...academic development" (Scholar \# 2) they hoped to achieve as a result of the participation in the VSP program. Scholars hoped they would experience "professional growth" (Scholars \#5 and \#11) during their time at UA and through their association with their faculty supervisor. The scholars utilized all available resources while in Canada to develop their research skills. Supervisors felt that the scholar needed to be situated close to the supervisor's office to ensure a positive outcome in the partnership. Different approaches were taken with the scholars, however most were given a workspace close to their supervisor, and various opportunities to meet and discuss their research with their supervisors. Most supervisors felt that the scholar they supervised was self-directed and motivated to make the most of their experience while they were in Edmonton. As one supervisor shared:

I have not met a single colleague from there that has come up that has not been extremely determined and very hard working and just keep trying until they become more proficient. (Supervisor \#2)

\subsubsection{Congruent fit between scholar and supervisor}

The majority of the supervisors recommended that the pairing of supervisors and scholars be given careful thought and consideration. It was important for the supervisor to have a reasonably strong publication record. Most supervisors felt that 
they were appropriately matched with the visiting scholar. Successful pairing was described as achieving congruency between the scholar's program of research and the supervisor's expertise:

The reason why I accepted was basically because she was studying something that was related (to my area of research), and there are so few of us around that are interested in that topic, that this was very nice. (Supervisor \#9)

Several of the scholars mentioned that they either knew their prospective supervisor before applying to the VSP program, or had carefully researched their area of research to ensure that they would be well matched:

I chose the post-doctoral fellowship at the University of Alberta because I knew my supervisor. She taught some classes in the subjects and offered a short graduate course in my graduate subject... I thought she had a very consistent research group and I was interested in taking part in her research group. (Scholar \# 10)

When the supervisor wasn't the best fit for the scholar, the outcomes for the VSP weren't achieved. One supervisor recommended that supervisors should be "chosen based on their expertise... [and] have time to mentor an international student..." (Supervisor \#12). The supervisor went on to say that as a result of the VSP experience, supervisors become "aware of the wider world, they increase their potential for joint partners and make a contribution to a country like Brazil...that's developing its research capacity." Although most of the supervisors felt that their match with scholars had been appropriate, they emphasized this factor. Positive outcomes were directly related to the alignment between the supervisor's area of research and the scholar's research interests. One supervisor believed that the VSP program must be:

...Well planned before the student arrives, and really, can I do anything for that student, and can that student fit in to what I'm doing in my research program, or within my range of research and substantive knowledge, so that there’s no disappointment. (Supervisor \#11)

\subsection{Program challenges}

\subsubsection{English skills (verbal/ written)}

Although a few scholars mentioned that the ability to "improve my English skills" (Scholar \# 3) was a goal of their participation in the VSP program, English skills (both verbal and written) were also the most common challenge identified by both scholars and supervisors. Many supervisors felt that the scholars' English language skills were not at an appropriate level upon arrival at UA. Following a placement test, scholars were enrolled in English language training through the UA Faculty of Extension. The training took place for four hours per day, five-days a week for seven weeks. After a 1-week break, the scholars typically enrolled in another training session, usually at the next level. Despite recognizing that English language training was essential, there were concerns with the amount of time scholars were involved in training.

Despite the significant investment in time, the English as a Second Language (ESL) courses were described as "excellent" by both the supervisors and visiting scholars. After the ESL courses were completed, the scholars' verbal English improved. Many supervisors felt that the scholars would have benefited from further development of their scholarly writing, based on their experience editing the scholars' proposals and papers.

So I developed a much greater appreciation for the difference between everyday English and scholarly English. And what a challenge it is for people to be able to write in a scholarly way in English...I think the big thing is acknowledging the amount of time it takes for faculty to work with international students because of the language. That needs to be acknowledged in any international program. Because the amount of one-on-one time is much greater than with Canadian students, just because of the language issue; you spend a great deal of time sorting out shared meanings with them. (Supervisor \#5) 
Overcoming the challenges related to language proved to be very labor intensive, and at time frustrating for supervisors and scholars alike. Although many supervisors cited English language skills as a program challenge, a few supervisors did not have this concern.

\subsubsection{Length of stay}

Concern about the scholars' length of stay was expressed by almost all of the scholars' supervisors. Visiting scholars stayed at UA for 4 months to 1 year, with most scholars staying for 6 months. Participating in one or two English courses during the first months of the VSP required a significant amount of time and energy on the part of the scholars. From the supervisors' perspective, adaptation to work and home life also took a few months. Several supervisors recommended that scholars stay at UA for one year to ensure that there was sufficient time to develop a working relationship and participate in scholarly activities, while at the same time improve their English language skills:

Six months is not a long time. I think there are high expectations that they come and they'll be getting publiccations out and doing all kinds of things within 6 months. That's very difficult when you're adjusting to a whole new country and culture and language. So I think that the more that you have planned ahead before the person arrives, the better, and the more language practice they have under their belt before they arrive, the better. (Supervisor \#2)

Many of the scholars voiced similar concerns that "6 months is a very short time" (Scholar \#8)

Because adaptation to, and contact with, a foreign language and culture was included in the 6 month period. Several scholars suggested that the VSP program be extended to 1 year.

\subsubsection{Selection of the faculty supervisor}

As mentioned previously, a good match between scholar and supervisor contributed to the success of the VSP, however, when there was not a good match, there was more work for the supervisor and potentially poorer outcomes for the scholar:

I think if we could have a little more connection before they actually come so that instead of let's say, trying to do their own study that's completely independent of my work that requires me to help them a lot, what we could do is say that if they're going to come up here and work with a professor here in a particular area, they have to work with that professor like other students do, within their research program. (Supervisor \#8)

Many of the scholars mentioned the challenges that resulted from not being connected to their supervisor prior to their arrival at the $\mathrm{U}$ of $\mathrm{A}$. The scholars believed that this may have hampered their preparation, adaptation and ability to participate in research activities:

I didn't have contact with my supervisor. What I sent her was the project. We didn't start working in advance, which is something I want to do in my next post-doctoral fellowship. That is, working with the supervisor before going there. (Scholar \# 8)

\subsection{Project outcomes}

\subsubsection{Ongoing relationships and expanded partnerships}

One of the overarching goals of the VSP was to develop ongoing collaborative relationships between the scholar and supervisors. Most supervisors felt that an ongoing research relationship was feasible if the research interests of the supervisor and scholar were closely aligned:

I mean 6 months, as far as I'm concerned, is just the beginning; you should then be able to keep working together once they've gone home, which is of course what [Scholar \#1] and [Scholar \#2] and I did. (Supervisor \#2) 
She's quite eager to come back up here perhaps in 2012, so I think we're going to have a much more ongoing relationship, which is good. She's trying to get me to come down there to be able to do some teaching and work with her on her work. (Supervisor \#8)

An interesting finding is that several UA supervisors are now working with their Brazilian scholars’ students:

We talked a lot about continuing to work together, so when she went back to Brazil, she introduced me, via e-mail with some of her students, so we have more than one generation of students working on the project. (Supervisor $\# 11)$

In addition to continued relations with their Brazilian scholars, two supervisors developed relationships with other universities in Brazil. For example one supervisor accessed UA funding to enable her to continue and expand her research partnerships in Brazil. Scholars highlighted on-going relationships with supervisors and the possibility of partnerships with other professionals at UA as benefits of the VSP. One scholar spoke about having the opportunity to "know other researchers, studies, [and] their projects” (Scholar \#3). Other scholars spoke the new research networks they had developed as result of the VSP:

From the personal viewpoint there's a very big gain, which is the opening of a network of relations and interlocution with a very big ethnic diversity, because you live with so many people who are seeking the same post-doctoral fellowship goal. (Scholar \#7)

Although some supervisors continued to work with their Brazilian scholars, the VSP program had not resulted in an ongoing research partnership for others.

\subsubsection{Benefits for the supervisors}

Overall the supervisors felt that the VSP was of value to themselves as well as to the scholars. They felt that through their participation, they had developed a greater understanding of other health care systems and truly collaborated in learning and teaching. Other common themes mentioned in the interviews included enrichment, broadening of perspectives, and the development of negotiation skills:

It's also rich for us, because we certainly learn a lot about other countries and other cultures and other ways of educating nurses and practicing nursing, so I think it's a really worthwhile reciprocal relationship. (Supervisor \#3)

One supervisor commented on the benefit of "working with different languages, people from different places and appreciating the richness of that. The richness is the existing difference." (Supervisor \#1)

Six supervisors stated that they had produced at least one publication together and two other supervisors had not produced any joint publications.

Certainly we have published some work together and presented some work together, and I think we will publish more. I know [Scholar \#1] will publish her work, I know, in English and in Portuguese; I’m very confident of that. (Supervisor \#2)

I think the biggest piece [challenge] was the publications, and I didn't see any publications as a result, which is very rare. (Supervisor \#7)

The development of a collaborative research program was an outcome of a productive experience. UA supervisors had different views on the value of the experience and value was defined differently by supervisors. Some of the supervisors described the value of the experience in relation to the ability to discuss similar issues in different contexts. Others spoke of the more objective value related to publication: 
When you engage in discussion with your colleagues in those contexts, the similarities are phenomenal in terms of so much you have in common and the issues that are-and I think it kind of confirms for you the kinds of directions you're going, and seeing that it is congruent with what is happening elsewhere. (Supervisor \#9)

So I think it helped to broaden my knowledge of one other aspect of the area of [supervisor's research area], because that was something I was very interested in working on. So it definitely enhanced my knowledge and learning in that area. (Supervisor \#12)

Three supervisors stated that supervising a Brazilian scholar did not provide any direct benefit to their research program. For example one supervisor said “I don't feel that it affected my job in any way” (Supervisor \#10) however, believed that working closely with an international student may have affected her personally. One of the supervisors had supervised two scholars and one of these was not working on a topic related to her program of research. She did not think that this student had helped to advance her research program. Several of the participants described reciprocal learning as a valuable outcome of the VSP program:

The Brazilian scholars coming in would have opportunities to work on a research team, to do presentations, to audit courses, and to learn from their Canadian supervisor. And the Canadian supervisors were invited to go to Brazil to share their knowledge with the nurse scholars and the students there...so both benefitted from the expertise of the other...I think it's a model program...But I had a lot of respect for the program....and what I saw was happening — the collaboration, the invitations back and forth to share in knowledge. (Staff \#2)

\subsubsection{Benefits for the scholars}

From the supervisors' perspective, perceived benefits to the Brazilian scholars were identified as: enhanced career opportunities; the ability to use the UA library facilities for their research; improved English skills; the development of networks with other doctoral students; and the development of their research program. For example, one supervisor noted that her student was promoted at her home University after completing the VSP at UA.

The outstanding library facilities provided by the UA were mentioned as a contributing factor in accomplishing research objectives.

We can use the infrastructure here to help the infrastructure there - to then come up with more robust publications in international journals. (Supervisor \#1)

The development of English language skills was noted by almost all supervisors as a significant benefit to the Brazilian scholars. Improved oral and written English was seen as a valuable outcome for the scholars. As one supervisor explained "after their English was at a certain level scholars demonstrated better functioning within an academic team and their writing improved" (Supervisor \#8). Many of the scholars published in English language journals after completing the VSP. English journals reach a larger audience, increasing exposure and potentially promoting the scholar in their careers. The creation of linkages with other students, scholars and research networks was another positive outcome of the VSP and could be a catalyst for future collaborative research.

We have people coming from different places, for example to do their doctoral studies. Although they're not part of this program (VSP), when they get here they hang out together. And then they can collaborate amongst themselves back home. (Supervisor \#11)

I had more direct contact with my supervisor's research group- that contact continues until today, we have monthly meetings, and even here in Brazil I participate in the meetings through Skype every month. (Scholar \#9)

The visiting scholars were involved in a variety of activities at the UA that helped to develop their research program. They audited graduate courses, completed literature reviews, prepared grant applications, worked on scholarly papers, and presented their research to faculty and students. Supervisors commented on the activities of the scholars who worked with them: 
She definitely increased her knowledge in relation to research because we did a literature review and it was in English. And she did a small grant application. (Supervisor \#3)

But it seemed to go very well, and then we spent the rest of the time developing the project and getting the paper done, which my understanding was an objective for her, because one of the things they really want to do is publish in refereed journals and get their work out in English. (Supervisor \#11)

The scholars outlined progress and positive outcomes in relation to their research, teaching and community service. The scholars described a wide range of benefits to their research programs as a result of participating in the VSP: the development of specific research skills, including methodological expertise; increased understanding of the research process; and connections to their supervisors research networks. Several scholars commented on their progress in publication of their scholarly work:

I've got one publication with my supervisor, and three others have been submitted, one's already accepted, it's in print, it hasn't been published yet but it's in print, and we're awaiting the response for the other two. (Scholar \#9)

[The VSP] resulted in 2 papers we published as a result of this study - 2 papers, one here in our Latin American Journal of Nursing and another in the Journal of Nursing Association, which is an important journal too. (Scholar $\# 11)$

Although the development of teaching skills was not a specific goal of the VSP, many scholars were able to observe undergraduate and graduate teaching while at UA. This made them reflect on their own teaching practice and introduce different approaches into their teaching:

So, it was very good, because everything I've learned, I started to teach and apply here at the school. To the extent that, in Brazil, I am a reference person for evidence-based practice. I have worked a lot with review methods, systematic reviews and integrative reviews with different professionals, including non-nurses. (Scholar \#4)

Another unintended outcome of the VSP was an increased awareness by some of the scholars of the connections between their research and the community service projects they were involved in:

So, in terms of community services, this possibility to participate in these spaces they have there [Edmonton] helped me a lot in the community service project I have here today... So that was a possibility to witness her [supervisor] experience with the elderly, to have material, of how she does that and when I return, today, everything, most of what I do in terms of community services results from that experience. So, I think that, for me, the most important focus it provided in terms of structure for these three things I develop here today, the community services are the strongest. (Scholar \#8)

\section{Discussion}

In 2004, the VSP was initiated as one component of a broader partnership between the University of São Paulo at EERP-USP, Brazil and the Faculty of Nursing, UA, Canada. The goal of the international partnership is to develop and strengthen collaborative relations between the two institutions. Although there has been research to evaluate the experiences of students who participate in an international experience ${ }^{[21]}$, there has been limited research to evaluate the experiences of, and benefits to, faculty members. Therefore, the purpose of the current study was to evaluate the outcomes of the VSP, including challenges to implementation, and the recommendations for future programs.

There were several limitations related to the evaluation of the VSP program. First, only scholars who had a basic knowledge of English were able to participate in the program. In addition, data was collected at only one point in time; this resulted in a variable length of time since completion of the program for both scholars and supervisors. Finally only one data collection approach, interviews, was used to evaluate the program. The team did not attempt to complete a 
quantitative evaluation (e.g. number of joint publications) of the outcomes of the program. Despite these limitations, the research teams at both sites were able to develop a more in-depth understanding of the program outcomes and challenges.

Overall, the program was highly successful from the perspective of both scholars and supervisors alike. Training for individual researchers has been described as the core component for research capacity building ${ }^{[7]}$ and was the primary focus of the Visiting Scholar Program. The visiting scholars were very appreciative of the opportunities for professional growth and research development that the VSP afforded. Similarly, Priest and colleagues ${ }^{[12]}$ reported that professional growth was one of the key benefits for researchers involved in a collaborative project to build nursing research capacity in the United Kingdom. These authors suggest that novice researchers need the opportunity for long-term, in-depth involvement with experienced research teams and to be provided with adequate support as they develop their research capacity. In the VSP, supervisors and scholars alike benefited from ongoing relationships and expanded partnerships as a result of their involvement in the VSP program. This was most likely to occur when the research interests of the supervisors and scholars were closely aligned. For example, in several instances scholars, following their return to Brazil continued to work with their former supervisors and supervisors were asked to mentor students of their former scholars and developed relationships and expanded their networks to other universities in Brazil.

Throughout the VSP we endeavored to ensure that our work together was respectful and mutually beneficial to both partners. Participants spoke about the mutual trust between partners and the mutual benefit for both partners. In addition we were open to other opportunities that the VSP provided. The hosting of additional scholars through funding agencies in Brazil provides one example of a new opportunity. Almost two decades ago, Gaillard ${ }^{[26]}$ outlined key principles for research collaboration among unequal partners. In an editorial Binka ${ }^{[27]}$ reaffirmed these principles and urged researchers to move beyond research partnerships based on "...scientific colonialism..." (p. 207) to true partnerships based on joint decision-making, shared governance, and mutual benefits. Allen and Ogilvie ${ }^{[1]}$ remind us of the importance of ensuring that international partnerships are 'respectful, reciprocal, and open to possibilities for international collaboration in research and scholarly endeavors' ${ }^{(p .79)}$. The development of mutually beneficial partnerships between high and LMIC countries increase the likelihood that the research partnership will be sustainable ${ }^{[7,26]}$.

The partnership between UA and EERP-USP that was established prior to the initiation of the VSP was instrumental to the success of the program. Participants in the current evaluation also commented on the importance of personal relationships and convergent research interests between scholars and the supervisors. Mayhew and colleagues ${ }^{[20]}$ evaluated the outcomes of a partnership to develop research capacity in the United Kingdom, South Africa and Thailand and reported that good personal relationships between members of partner institutions were critical to the development of research capacity in a partnership among institutions in the three countries. In addition they reported that there was a significant strengthening of individual research skills and some institutional strengthening in the partners in the south.

Nchinda ${ }^{[8]}$ reminds us that research capacity building includes not only training of researchers, but also the provision of institutional support to the institutions where the researchers will work. The commitment to internationalization that was evident at both sites helped to ensure that there was broad institutional support for the VSP. Nchinda also highlights the importance of identifying suitable trainees and providing adequate support and career opportunities for trainees on their return as critical factors to sustain international research capacity building initiatives. The identification of suitable scholars for the VSP was primarily the responsibility of the leadership team at USP, with input from the Global Nursing Office in the Faculty of Nursing at UA.

The sustainability and success of international experiences is also enhanced by ensuring adequate human and material resources ${ }^{[21]}$ and facilitating partnership research grants between the two participating organizations ${ }^{[8]}$. The generous financial contribution of the private donor ensured that there were sufficient resources to implement the project as planned.

Several authors ${ }^{[4,21,25]}$ highlighted the importance of involving colleagues from each partner country in the publication of the results of international experiences as an important principle to promote true partnerships and a strategy to build 
research capacity. In the VSP both partners are participating in the analysis and dissemination process. The Brazilian research team has led the analysis of the findings from the interviews with the scholars, while the Canadian team has led the analysis of the interviews from the supervisors. Similarly, the Canadian partners are leading the dissemination of findings related to advancing scholarship among faculty members while the Brazilian partners will lead the dissemination of the findings related to the cross-cultural experiences of participants in the program.

In the current program we experienced challenges related to language, length of the program, and at times, inadequate pre-planning between the scholar and supervisor. The selection of scholars who had sufficient English skills to benefit from the VSP was an ongoing challenge that UA and EERP-USP continually collaborated on to improve outcomes. It has been proposed to scholars that they stay at the UA for a longer period however this has been difficult for scholars with young families. A teleconference meeting between the scholar and supervisor prior to beginning the VSP has been added to the planning process to ensure that the scholars' objectives and learning needs are closely aligned with the supervisors' skills. Although working collaboratively across institutions adds complexity to the research process and takes time it increases the robustness of the research ${ }^{[12]}$.

Overall the leadership team at each site, the scholars, and the supervisors believed that the VSP was successful. There are several factors that we feel were key to the success of the VSP program and recommend that they be considered in the design of future similar programs: commitment to internationalization at each site; a well-established partnership between the two sites; and sufficient financial resources to provide a supportive, enabling environment for the scholars to develop their own research capacity and for both scholars and supervisors to build new research networks. In addition we would recommend that visiting scholar programs be a minimum of six, but preferably twelve months and that language training be integral to the scholars' training as required. Benefits are maximized when there is a good fit between the research training needs of the scholar and the research program of the supervisor and when planning is started well in advance of the program initiation.

\section{Acknowledgement}

We would like to acknowledge the generous donation of Mr. Gordon Arnell to initiate the program in 2004. The financial contribution was renewed in 2007 and is expected to enable visiting scholars to participate in the program until 2014. The research team would like to acknowledge the contributions of Dayna Kliachik who conducted the interviews and coded the data at the UA site.

\section{Conflict of interest}

All authors declare that there is no conflict of interest.

\section{References}

[1] Allen M, Ogilvie, L. Internationalization of higher education: potentials and pitfalls for nursing education. Int Nurs Rev. 2004; 51: 73-80. http://dx.doi.org/10.1111/j.1466-7657.2003.00226.x

[2] Mill J, Astle B, Ogilvie L, Gastaldo, D. Linking global citizenship, undergraduate nursing education, and professional nursing: curricular innovation in the 21st century. Adv Nurs Sci. 2010; 33(3): E1-E11. http://dx.doi.org/10.1097/ANS.0b013e3181eb416f

[3] Lepp M, Halabi J, Määttä S. Jordanian nursing faculty experiences of participation in international exchange programmes with Sweden. Div Health Care. 2011; 8: 181-8.

[4] McAuliffe M, Cohen M. International nursing research and educational exchanges: A review of the literature. Nurs Outlook. 2005; 53: 21-25. http://dx.doi.org/10.1016/j.outlook.2004.10.004

[5] Harrowing J, Mill J, Spiers J, Kulig J, Kipp W. (2010). Culture, context and community: ethical considerations for global nursing research. Int Nurs Rev. 2010; 57(1): 70-77. http://dx.doi.org/10.1111/j.1466-7657.2009.00766.x

[6] Kitua AY, Corrah T, Herbst K, Nyirenda, T, Agwale S, Makanga M, et al. Strengthening capacity, collaboration, and quality of clinical research in Africa: EDCTP Networks of Excellence. Tanzania J Health Res. 2009; 11(1): 51-54.

http://dx.doi.org/10.4314/thrb.v11i1.43253

Published by Sciedu Press 
[7] Lansang MA, Dennis R. Building capacity in health research in the developing world. Bulletin WHO. 2004; 82(10): 764-770.

[8] Nchinda TC. Research capacity strengthening in the south. Soc Sci Med. 2002; 54: 1699-1711. http://dx.doi.org/10.1016/S0277-9536(01)00338-0

[9] Boland MG, Kamikawa C, Inouye J, Latimer RW, Marshall S. Partnership to build research capacity. Nurs Econ. 2010; 28(5): 314-336. PMid:21158252

[10] Nowell B, Harrison LM. Leading change through collaborative partnerships: A profile of leadership and capacity among local public health leaders. J Prev Interven Com. 2011; 39(1); 19-34. http://dx.doi.org/10.1080/10852352.2011.530162

[11] Poulsen AA, Bush R, Tirendi J, Ziviani J, Abbott R, Macdonald D et al. Research around practice partnerships: An example of building partnerships to address overweight and obesity in children. Aust J Primary Health. 2009; 15(4): 285-293. http://dx.doi.org/10.1071/PY09005

[12] Priest H, Segrott J, Green B, Rout A. Harnessing collaboration to build nursing research capacity: A research team journey. Nurs Educ Today. 2007; 27: 577-597. http://dx.doi.org/10.1016/j.nedt.2006.08.019

[13] Spadaro AJ, Grunbaum JA, Dawkins NU, Wright DS, Rubel SK, Green DC et al. Training and technical assistance to enhance capacity building between prevention research centers and their partners. Prev Chronic Dis. 2011; 8(3): A65-A65. PMid:21477505

[14] Rojas MA, Lozano JM, Rojas MX. International collaborative research: A Colombian model that promotes infant health and research capacity. J Perinat. 2007; 27(12): 738-743. http://dx.doi.org/10.1038/sj.jp.7211827

[15] Zumla A, Huggett J, Dheda K, Green C, Kapata N, Mwaba P. Trials and tribulations of an African-led research and capacity development programme: The case for EDCTP investments. Trop Med Inter Health. 2010; 15(4): 489-494. http://dx.doi.org/10.1111/j.1365-3156.2010.02479.x

[16] Lazarus JV, Wallace SA, Liljestrand J. Improving African health research capacity. Scand J Pub Health. 2010; 8(6); 670-671. http://dx.doi.org/10.1177/1403494810372265

[17] Tomatis C, Taramona C, Rizo-Patrón E, Hernández F, Rodríguez P, Piscoya A et al. Evidence-based medicine training in a resource-poor country, the importance of leveraging personal and institutional relationships. J Eval Clin Practice. 2011; 17(4): 644-650. http://dx.doi.org/10.1111/j.1365-2753.2011.01635.x

[18] Potter C, Brough R. Systemic capacity building: A hierarchy of needs. Health Pol Plan. 2004; 19(5): 336-345, http://dx.doi.org/10.1093/heapol/czh038

[19] Coloma J, Harris E. From construction workers to architects: Developing scientific research capacity in low-income countries. Plos Bio. 2009; 7(7), e1000156. http://dx.doi.org/10.1371/journal.pbio.1000156

[20] Mayhew SH, Doherty J, Pitayarangsarit S. Developing health system research capacities through north-south partnership: An evaluation of collaboration with South Africa and Thailand. Health Res Pol Sys. 2008; 6(8): 1-12. http://dx.doi.org/10.1186/1478-4505-6-8

[21] Kulbok P, Mitchell E, Glick D, Greiner D. International experiences in nursing education: A review of the literature. Int J Nurs Educ Schol. 2012; 9(1): 1-21. http://dx.doi.org/10.1515/1548-923X.2365

[22] Mill J, Mendes I, Ventura C, Johnson L., Kliachik D, Brito E. Evaluation of the Visiting Scholar Program. University of São Paulo at Ribeirão Preto College of Nursing (EERP-USP), Brazil and the Faculty of Nursing, University of Alberta (UA), Canada. 2012.

[23] Thorne S, Reimer-Kirkham, S, \& MacDonald-Emes, J. Interpretative description: A noncategorial qualitative alternative for developing nursing knowledge. Res Nurs Health. 1997; 20: 169-177. http://dx.doi.org/10.1002/(SICI)1098-240X(199704)20:2<169::AID-NUR9>3.0.CO;2-I

[24] Thorne S. Qualitative research in the applied disciplines. In Interpretative Description (pp . 23-36). Walnut Creek, CA: Left Coast Press.

[25] Morse, J. M. (1994). "Emerging from the data": The cognitive processes of analysis in qualitative inquiry. In J. M. Morse (Ed.), Critical issues in qualitative research methods (pp. 23-43). Thousand Oaks, CA: Sage.

[26] Gaillard JF. North-south research partnerships: Is collaboration possible between unequal partners? Know Pol. $1994 ;$ 7(2): 31-63. http://dx.doi.org/10.1007/BF02692761

[27] Binka F. North-South research collaborations: A move towards a true partnership? Trop Med Int Health. 2005; 10(3): 207-209. http://dx.doi.org/10.1111/j.1365-3156.2004.01373.x 